\title{
Multi-objective optimization of arc welding parameters - the trade-offs between energy and thermal efficiency
}

\author{
YAN Wei ${ }^{l}$, ZHANG Hua ${ }^{l}, J I A N G$ Zhi-gang ${ }^{l}$, K. K. B. HON ${ }^{2 *}$
}

(1) School of Machinery and Automation, Wuhan University of Science and Technology,

Hubei 430081, China

(2) School of Engineering, University of Liverpool, Liverpool 69 3GH, UK

\begin{abstract}
Arc welding is a common joining method, which is usually characterized by high energy consumption and low energy efficiency. With the recent focus on energy management and carbon emissions, energy saving has become a priority for manufacturing industry. In the past, energy saving technologies for welding had primarily aim for heat source improvement, with less emphasis on parameter optimization. It is obvious that parameter optimization methods for energy reduction can be applied to existing equipment where large investments are not required. Therefore, a multi-objective optimization method based on Fitness Sharing Genetic Algorithm (FSGA) is proposed for energy reduction and thermal efficiency improvement of arc welding process in this paper. Two objectives including energy consumption and thermal efficiency are considered in the optimization model with two independent variables, namely welding current and welding velocity. Additionally, the limits of the variables and welding quality are also considered. A case study of rail track joints using Shielded Metal Arc Welding (SMAW) is conducted for the verification of the proposed optimization method. Finally, the optimization method and results are analyzed with the actual data and Genetic Algorithm (GA) respectively. Comparison with actual data shows that the proposed approach has a more significant effect on energy saving and thermal efficiency improvement. The optimization analysis shows that FSGA has a better population diversity and global search capability compared with GA.
\end{abstract}

\section{Key words:}

Multi-objective optimization

Arc welding

Energy consumption

Thermal efficiency

Fitness sharing genetic algorithm (FSGA) 


\begin{tabular}{|c|c|c|}
\hline \multicolumn{3}{|l|}{ Nomenclature } \\
\hline specific heat of weld material $\left[\mathrm{KJ} / \mathrm{Kg}^{\circ} \mathrm{C}\right]$ & $q_{2}$ & enthalpy heat $[\mathrm{KJ}]$ \\
\hline $\begin{array}{ll}E_{0} & \begin{array}{l}\text { energy consumption in one working } \\
\text { cycle }[\mathrm{KWh}]\end{array}\end{array}$ & $q_{3}$ & dispersed heat $[\mathrm{KJ}]$ \\
\hline energy consumption objective [KWh] & $\Delta S_{m}$ & latent heat of the fusion weld material \\
\hline depth of fusion $[\mathrm{mm}]$ & $S^{m}$ & cross-sectional area of weld line $\left[\mathrm{mm}^{2}\right]$ \\
\hline weld width [mm] & $S_{m}$ & enthalpy of molten metal per unit weight \\
\hline excess weld metal $[\mathrm{mm}]$ & $T_{0}$ & duration of one working cycle [min] \\
\hline weld length $[\mathrm{mm}]$ & $T_{T}$ & duration of whole welding process [min] \\
\hline rated welding current $[\mathrm{A}]$ & $T_{m}$ & melting point of weld material $\left[{ }^{\circ} \mathrm{C}\right]$ \\
\hline welding current $[\mathrm{A}]$ & $U_{N}$ & rated arc voltage $[\mathrm{V}]$ \\
\hline rated utilization factor [\%] & $U$ & welding voltage [V] \\
\hline utilization factor $[\%]$ & $V$ & welding velocity $[\mathrm{mm} / \mathrm{s}]$ \\
\hline $\begin{array}{l}P_{0} \text { arc welding machine power in idle state } \\
\text { in one working cycle }[\mathrm{KW}]\end{array}$ & $\eta_{2}$ & power factor of arc welding machine [\%] \\
\hline $\begin{array}{l}P_{l} \text { arc welding machine power in loading } \\
\text { state in one working cycle [KW] }\end{array}$ & $\eta_{t}$ & thermal efficiency [\%] \\
\hline$q_{0} \quad$ arc output heat $[\mathrm{KJ}]$ & $\eta$ & thermal efficiency objective \\
\hline$q$ heat input to metal $[\mathrm{KJ}]$ & $\gamma$ & proportion of weld material \\
\hline$q_{l}$ fusion latent heat $[\mathrm{KJ}]$ & & \\
\hline
\end{tabular}

\section{Introduction}

With recent continual increase in energy demand and constraints in carbon emissions, energy saving has become a priority for manufacturing industry. Increasing legislative environmental pressure and public environmental awareness are driving manufacturers to take definite measures to improve their environmental performance (Du et al., 2015). Additionally, energy costs have become major agenda items of manufacturing enterprises (Kilian, 2008). From a global perspective, statistical data from the International Energy Agency (IEA) shows that manufacturing industry consumes over $30 \%$ of the entire electricity produced, and generates at least $36 \%$ of the total global carbon dioxide emission (IEA, 2007). In China, energy consumption of the manufacturing sector is more than $50 \%$ of the entire electricity produced (Tang et al., 2006).

In the last few decades, energy-saving methods for arc welding mainly focused on new equipment and technology, especially the improvement of welding heat sources such as plasma arc and laser beam, etc. However, the potential for energy reduction via welding parameter optimization methods, which examine the relationship between welding parameters and energy consumption, has been largely ignored. While the energy saving impact of the latter approach may not be as great as the previous one, it should be noted that such methods could be readily applied to existing equipment and processes without any extra investment. Additionally, arc-welding machines are identified as one of the high energy-consuming equipment in China, and are widely used with high growth rate. For instance, more than 4 million of arc welding machines are produced annually from 2008-2012 (China Electrical Equipment Industry Association, CEEIA, 2012), but the average thermal efficiency is less than 75\% (Wang, 2007). A case from Guan (1982) shows that thermal efficiency of DC manual arc welding is only $23.5 \%$. Due to the huge number of arc welding machines in use, the impact of energy reduction could be enormous. As an 
example, if the energy consumption of arc welding is reduced by $1 \%$, the total energy reduction could be more than 2 billion kilowatt per year. Under such circumstances, a review of energy consumption of welding processes could provide a useful guide for energy saving.

Recently, numerous investigations are reported on welding parameter optimization. Gonçalves et al. (2010) studied the thermal efficiency optimization method of Tungsten Inert Gas (TIG) welding based on the golden section approach. Dey et al. (2009) investigated the drop penetration welding area under the condition of minimum welding parameters by using GA. Islam et al. (2014) applied coupled GA and Finite Element Analysis (FEA) methods to establish a welding parameters optimization system for the welded product quality. Feng et al. (2012) studied the relationship between welding velocity and thermal efficiency in $\mathrm{CO}_{2}$ shielded metal arc welding and established a maximum thermal efficiency optimization model. Kumar et al. (2014) studied a welding parameters optimization method of laser transmission welding of the maximum weld joint strength and minimum width based on Gray Scale Taguchi method. Wang et al. (2010) used Gray Relational Analysis (GRA) method for maximizing the strength of arc welding. A different approach was adopted by Luo (2013) who used Generalized Regression Neural Network (GRNN) to minimize the carbon emissions of $\mathrm{CO}_{2}$ shielded metal arc welding. The multi-objective optimization approach was also taken by a number of investigations. For instance, quality and energy, costs and energy, and quality and costs optimization of welding process were studied respectively by Khan et al. (2011), Liu et al. (2006), and Luis et al. (2011).

Most of the above literature addressed the optimization of welding processes with the traditional single objective model such as quality or cost. Some literatures are concerned with energy saving and environmental emissions. However, there is hardly any reported research on the correlation between energy consumption and thermal efficiency of arc welding.

Based on the above review, a multi-objective parameters optimization model of arc welding for energy reduction and thermal efficiency improvement is presented in this paper. In this model, energy consumption and thermal efficiency are the optimization objectives, welding current and welding velocity as independent variables, and the constraints consist of the limits of arc welding machine and product specifications. The FSGA is applied as the solution method. Finally, a SMAW example of rail track joints is given for the verification of the feasibility of the model and validation of the proposed methodology.

\section{Energy consumption and thermal efficiency analysis of arc welding processes}

In arc welding processes, an intense electrical arc is used as the heat source to melt metallic materials locally, which is joined upon solidification. The energy consumption is affected by welding parameters especially welding current, welding voltage and welding velocity.

Thermal efficiency is another critical parameter to affect welding quality and environmental emissions (Eagar, 1990), which can be described as the ratio of absorption heat of metal $(q)$ and release heat of $\operatorname{arc}\left(q_{0}\right)$ in unit time (Wang, 2007). This implies that the higher thermal efficiency, the lower is the energy dissipation, and the environmental impact caused by the radiation will be 
less. However, $q$ contains fusion latent heat $\left(q_{1}\right)$, enthalpy heat $\left(q_{2}\right)$ and dispersed heat $\left(q_{3}\right)$. Only $q_{1}$ is used to melt metal, $q_{2}$ may cause metal overheating and $q_{3}$ is related to the heat exchange with the ambient environment. Hence, previous research (Guan et al. 1982; Ai et al. 1983) suggested the use of the ratio of $q_{1}$ and $q_{0}$ to reflect thermal efficiency of welding process. In this paper, the latter definition is used, namely $q_{1} / q_{0}$. Additionally, thermal efficiency is also related to welding parameters such as welding voltage, welding current and welding velocity, etc.

\section{Establishment of arc welding multi-objective optimization model}

\subsection{Independent variables and optimization objectives}

As mentioned in Section 2, welding voltage, welding current and welding velocity are the major factors for energy consumption and thermal efficiency of arc welding process. However, welding voltage can be calculated with an empirical formula by welding current as given in the China National Standard (GB15579.1-2004). In order to reduce computation, welding voltage is regarded as a function of welding current in this paper. Therefore, welding current and welding velocity are selected as the independent variables, and minimizing energy consumption and maximizing thermal efficiency are considered as the two optimization objectives.

\subsection{Energy consumption function}

With reference to the China National Standards (GB/T8118-2010), the arc welding process is divided into several working cycles. In one working cycle, there are two different states of an arc-welding machine, namely the loading state and the idle state. The duration of each state is determined by utilization factor $(k)$. Therefore, the energy consumption of arc welding process in one working cycle can be expressed as $\mathrm{Eq}(1)$ :

$$
E_{0}=\left[P_{1} k+P_{0}(1-k)\right] T_{0}
$$

where, $E_{0}$ is the energy consumption in one working cycle, $P_{l}$ is the arc welding machine power in loading state per one working cycle, $P_{0}$ is the arc welding machine power in idle state per one working cycle, $T_{0}$ is the duration of one working cycle.

In $\mathrm{Eq}(1), k$ can be obtained by $\mathrm{Eq}(2)$.

$$
k=k_{N}\left(\frac{I_{N}}{I}\right)^{2}
$$

where, $k_{N}$ and $I_{N}$ represent the rated utilization factor and the rated current of the arc welding machine respectively, $I$ is welding current. If $k \geq 1$, it means that the arc welding machine is working continuously in the working cycle, and under this condition, $k=1$.

$P_{l}$ in $\mathrm{Eq}(1)$ can be calculated by $\mathrm{Eq}(3)$.

$$
P_{1}=U I / \eta_{2}
$$

where, $\eta_{2}$ is the power factor of the arc-welding machine, $U$ is the welding voltage.

The total welding time $\left(T_{T}\right)$ is determined by the weld length and welding velocity, combining with previous analysis of working cycles, $T_{T}$ can be calculated by $\mathrm{Eq}(4)$ : 


$$
T_{T}=\frac{H}{V}=\left(\left[\frac{H}{k T_{0} V}\right]+1\right) T_{0}
$$

where, $H$ is the weld length, $V$ is the welding velocity, $\left[\frac{H}{k T_{0} V}\right]+1$ denotes the number of working cycles of arc-welding machine in the complete welding processes.

From the above discussions, the total energy consumption of arc welding processes can be represented by $\mathrm{Eq}(5)$.

$$
E_{T}=\left[k P_{1}+(1-k) P_{0}\right] \cdot\left(\left[\frac{H}{k T_{0} V}\right]+1\right) T_{0}
$$

As stated earlier, welding voltage can be obtained with welding current (GB15569.1-2004). For example, for manual arc welding processes, $U$ can be expressed as follows:

$$
\left\{\begin{array}{l}
I \leq 600 A: U=20+0.04 I \\
I \geq 600 A: U=44
\end{array}\right.
$$

For convenience, $f(I)$ is used to replace $U$. Therefore, energy consumption function of arc welding processes is represented by $\mathrm{Eq}(6)$.

$$
\begin{aligned}
E_{T} & =\left[k P_{1}+(1-k) P_{0}\right] \cdot\left(\left[\frac{H}{k T_{0} V}\right]+1\right) T_{0} \\
& =\left[k_{N}\left(\frac{I_{N}}{I}\right)^{2} \cdot \frac{I \cdot f(I)}{\eta_{2}}+\left(1-k_{N}\left(\frac{I_{N}}{I}\right)^{2}\right) P_{0}\right] \cdot\left(\left[\frac{H \cdot I^{2}}{k_{N} I_{N}^{2} T_{0} V}\right]+1\right) T_{0}
\end{aligned}
$$

\subsection{Thermal efficiency function}

From the discussions in Section 2, the thermal efficiency $\left(\eta_{t}\right)$ can be expressed using the proposed method of $\mathrm{Ai}$ (1983), which can be expressed as Eq(7).

$$
\eta_{t}=\frac{q_{1}}{q_{0}}=\frac{S V \gamma\left(C T_{m}+\Delta S_{m}\right)}{0.24 I \cdot f(I)}
$$

where, $S$ is the cross-sectional area of the weld line, $V$ is the welding velocity, $\gamma$ is the proportion of weld material, $C$ is the specific heat of weld material, $T_{m}$ is the melting point of weld material, $\Delta S_{m}$ is the fusion latent heat of weld material, 0.24 is the conversion factor of the arc welding machine.

\subsection{Constraints}

The parameters of arc welding are constrained by the arc welding machine, welding process and welding quality etc. Therefore, all operating parameters shall be within the constraints in the optimized solution.

(1) Welding current constraint: In arc welding process, the welding current is required to meet two constraints. The first one is due to the arc welding machine, which has both minimum 
current $\left(I_{\min }\right)$ and maximum current $\left(I_{\max }\right)$ limits, namely $I_{\min } \leq I \leq I_{\max }$. The second one is related to operating restriction, which requires for the need of matching the welding rod diameter (d). The welding handbook (Wang, 2010) stipulates the calculation coefficient $K_{\min }$ and $K_{\max }$ of welding current according to welding rod diameters, namely $K_{\min } \cdot d \leq I \leq K_{\max } \cdot d$. Therefore, welding current constraints can be expressed as $\mathrm{Eq}(8)$.

$$
\max \left(I_{\min }, K_{\min } \cdot d\right) \leq I \leq \min \left(I_{\max }, K_{\max } \cdot d\right)
$$

(2) Heat input constraint: During arc welding, if the input heat to the weld pool is too large that could cause overheating, if too small the metal could not become fully molten thereby affecting the welding quality. The required heat $\left(q_{1}\right)$ for the weld pool in unit time is related to the physical properties of welded element and welding velocity. Hence, heat input constraints can be transformed into the welding velocity constraints as shown in $\mathrm{Eq}(9)$.

$$
\frac{q_{1 \min }}{S \gamma S_{m}} \leq V \leq \frac{q_{1 \max }}{S \gamma S_{m}}
$$

where, $S_{m}$ is enthalpy of molten metal per unit weight.

(3) Welding quality constraints: The welding seam shape is a primary index for welding quality. There is established guideline for all types of welding appearance in order to ensure welding quality. Major dimensional parameters of the welding seam shape are characterized as depth of fusion $\left(h_{1}\right)$, weld width $\left(h_{2}\right)$ and excess weld metal $\left(h_{3}\right)$. According to the China National Standard (GB10854-89), the ranges of these parameters are shown in $\mathrm{Eq}(10)$.

$$
\begin{aligned}
& h_{1 \min } \leq h_{1} \leq h_{1 \max } \\
& h_{2 \min } \leq h_{2} \leq h_{2 \max } \\
& h_{3 \min } \leq h_{3} \leq h_{3 \max }
\end{aligned}
$$

\subsection{Multi-objective optimization model}

Based on the above analysis, energy consumption and thermal efficiency optimization of arc welding is a typical constrained multi-objective optimization problem. In order to maintain the consistency of the optimization objectives, thermal efficiency objective can be expressed as the reciprocal of $\eta_{t}$ in this paper, as shown in $\mathrm{Eq}(11)$.

$$
\eta=\frac{1}{\eta_{t}}=\frac{0.24 I \cdot f(I)}{S V \gamma\left(C T_{m}+\Delta S_{m}\right)}
$$

Therefore, the complete mathematical model of this multi-objective optimization problem can be expressed as $\mathrm{Eq}(12)$. 


$$
\begin{aligned}
& \min f(I, V)=\left(\min f_{E_{T}}(I, V), \min f_{\eta}(I, V)\right) \\
& \text { s.t. }\left\{\begin{array}{l}
\max \left(I_{\min }, K_{\min } \cdot d\right) \leq I \leq \min \left(I_{\max }, K_{\max } \cdot d\right) \\
\frac{q_{1 \min }}{S \gamma S_{m}} \leq V \leq \frac{q_{1 \max }}{S \gamma S_{m}} \\
h_{1 \text { min }} \leq h_{1} \leq h_{1 \max } \\
h_{2 \min } \leq h_{2} \leq h_{2 \max } \\
h_{3 \text { min }} \leq h_{3} \leq h_{3 \max }
\end{array}\right.
\end{aligned}
$$

where, $f(I, V)$ is the objective function, and it refers to minimizing energy consumption and maximizing thermal efficiency, $f_{E_{T}}(I, V)$ is energy consumption objective function, $f_{\eta}(I, V)$ is thermal efficiency objective function.

\section{Solving Optimization model based on FSGA}

Due to the difficult to obtain the global optimal solution of GA in complex function optimization, 'Fitness sharing genetic algorithm' (FSGA) is proposed for solving this model. FSGA sets a sharing fitness that reflects the degree of similarity between individuals to create a niche environment, which can achieve maintenance of population diversity through adjusting the individual fitness (Goldberg et al. 1987). Compared with GA, FSGA has an additional diversity protection mechanism of selection strategy to ensure obtaining the local and global optimal solution (Deb. 1989; Wu et al. 2005; Xiao et al. 2012). The solution procedure of FSGA is discussed in detail as follows.

\section{a. Encoding operator}

Floating-point numbers are used to code the independent variables $I$ and $V$, whereas individuals chromosome coding are expressed as $\mathrm{Eq}(13)$.

$$
P=[I \mid V]=\left[I_{1}, I_{2}, \cdots, I_{n} \mid V_{1}, V_{2}, \cdots, V_{n}\right]
$$

where, $n$ is the population size.

\section{b. Selection operator}

(1) Calculating the sharing degree of all population individuals.

i) Using the Euclidean distance $d_{i j}$ to describe the relationship of two individuals $X_{i}$ and $X_{j}$, as shown in $\operatorname{Eq}(14)$.

$$
d_{i j}=\sqrt{\left(f_{E_{T}}\left(x_{i}\right)-f_{E_{T}}\left(x_{j}\right)\right)^{2}+\left(f_{\eta}\left(x_{i}\right)-f_{\eta}\left(x_{j}\right)\right)^{2}}
$$

ii) Calculating the individuals sharing degree $S_{i}$ using the proposed method of Goldberg et al. (1987) and Deb (1989), as shown in $\mathrm{Eq}(15)$ and $\mathrm{Eq}(16)$.

$$
\operatorname{sh}\left(d_{i j}\right)=\left\{\begin{array}{lc}
1-\frac{d_{i j}}{\sigma_{s h}} & d_{i j}<\sigma_{s h} \\
0 & \text { otherwise }
\end{array}\right.
$$




$$
S_{i}=\sum_{j=1}^{n} \operatorname{sh}\left(d_{i j}\right)
$$

where, $\operatorname{sh}\left(d_{i j}\right)$ is the sharing function, $\sigma_{s h}$ is the niche genetic radius.

(2) Adjusting the individual $X_{i}$ 's fitness function $f_{s h}\left(X_{i}\right)$ with $\operatorname{Eq}(17)$ to ensure the population diversity and to control the proliferation inhibition of similar individuals.

$$
f_{s h}\left(X_{i}\right)=\left\{\begin{array}{l}
f_{E_{T}}\left(X_{i}\right) / S_{i} \\
f_{\eta}\left(X_{i}\right) / S_{i}
\end{array}\right.
$$

\section{c. Crossover operator}

The individual arithmetic crossover method is used for new individual production as shown in $\mathrm{Eq}(18)$.

$$
\left\{\begin{array}{l}
X_{i}^{t+1}=\alpha X_{j}^{t}+(1-\alpha) X_{i}^{t} \\
X_{j}^{t+1}=\alpha X_{i}^{t}+(1-\alpha) X_{j}^{t}
\end{array}\right.
$$

In $\mathrm{Eq}(18), X_{i}^{t+1}$ and $X_{j}^{t+1}$ are offspring individual $X_{i}$ and $X_{j}$ respectively, $X_{i}^{t}$ and $X_{j}^{t}$ are parent individual $X_{i}$ and $X_{j}$ respectively, $\alpha$ is the scale factor.

\section{d. Mutation operator}

If the mutation step is $\Delta$, the gene value range of the $t$ generation change point $x_{k}$ is $\left[U_{\min }^{k}, U_{\max }^{k}\right]$, so the new genetic value $x_{k}^{\prime}$ is calculated as follows.

$$
\begin{gathered}
x_{k}^{\prime}= \begin{cases}x_{k}+\Delta\left(t, U_{\max }^{k}-x_{k}\right) & \alpha=0 \\
x_{k}-\Delta\left(t, x_{k}-U_{\min }^{k}\right) & \alpha=1\end{cases} \\
\Delta(t, y)=y \cdot\left(1-r^{(1-t / T) b}\right)
\end{gathered}
$$

where, $r$ is the random number within the range $[0,1], T$ is the biggest evolutionary population, $b$ is the system parameter.

Given all that, the basic flow process chart of FSGA is shown in Figure 1. 


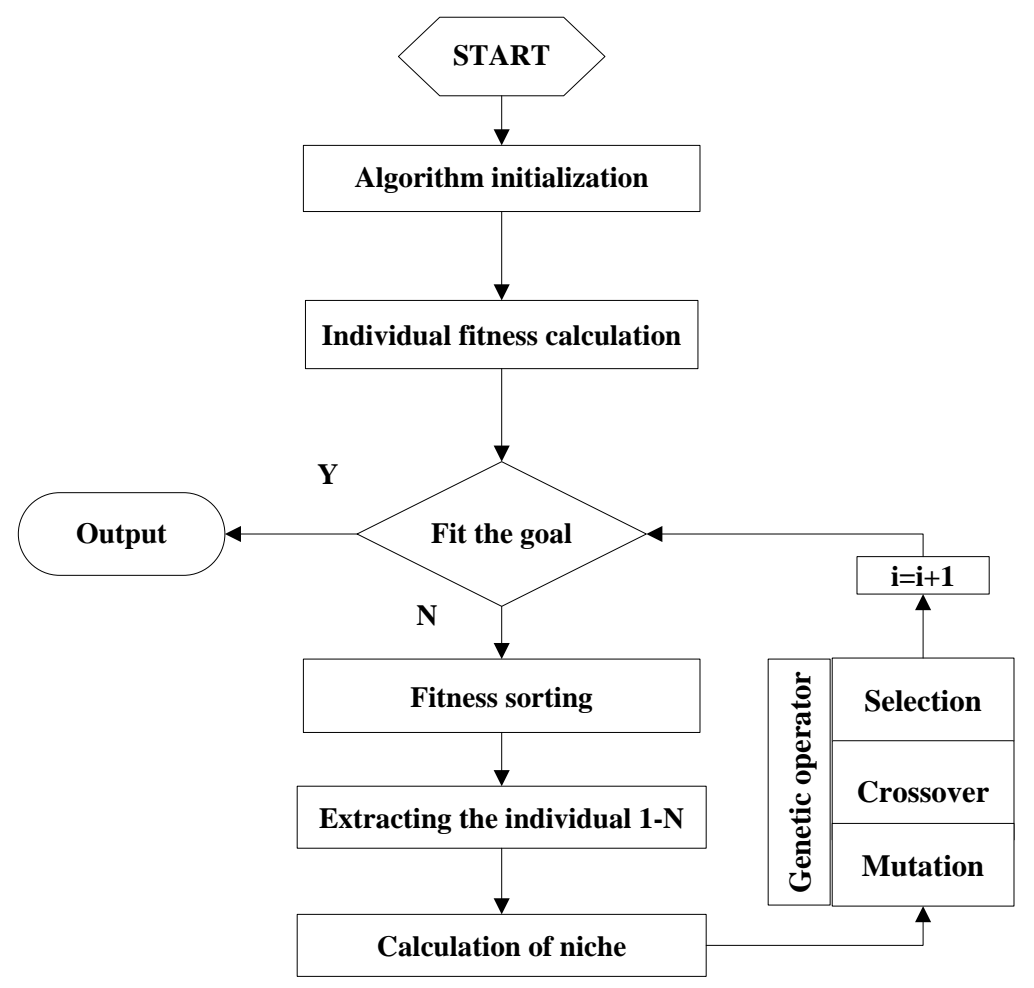

Figure 1 Flow process chart of FSGA optimization.

\section{Case study}

In this case study, a SMAW process of rail track is presented to demonstrate the proposed approach. The grades of this rail track are E360, the welding equipment is DC manual arc welding machine YD-400AT3, and the welding rod is high strength steel wire J607RH. A schematic diagram of the track joint is shown in Figure 2.

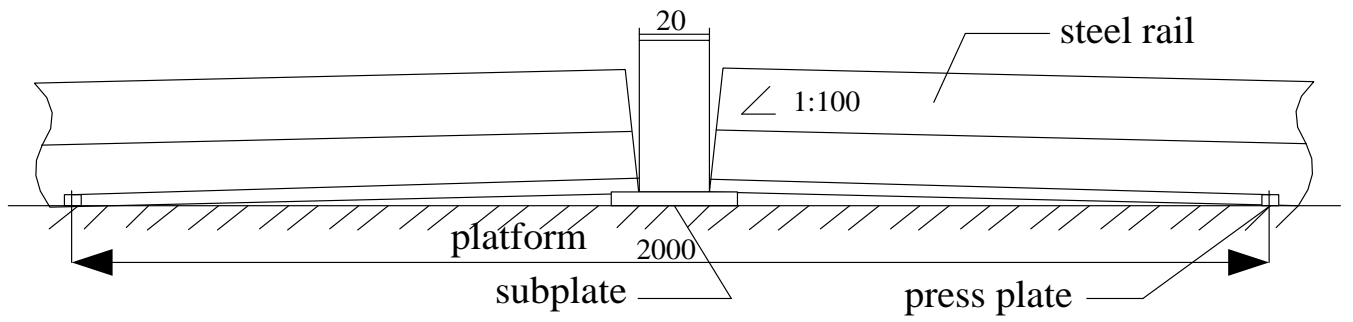

Figure 2 A rail track joint, all dimensions are in $\mathrm{mm}$.

The following steps are taken to calculate energy consumption and thermal efficiency of the SWAM process:

a) Listing the necessary parameters of welding equipment, welding rod and the rail track, which are given in Table 1.

b) Calculating the objective and constraint functions with these parameters.

c) Compiling the program code of FSGA using Matlab 2013b, and setting the algorithm parameters as follows: the population size was 60, the maximum generation was 200, the convergence value was 0.01, and the crossover and mutation probabilities are 0.8 and 0.05 , respectively.

d) Solving the multi-objective optimization function, the distribution of the Pareto optima are 
shown in Figure 3(a), and the corresponding detailed information of each Pareto optimum are listed in Table 2.

Table 1 Parameters of the case study

\begin{tabular}{ccccccc}
\hline \multirow{2}{*}{$\begin{array}{c}\text { Welding } \\
\text { equipment }\end{array}$} & $\begin{array}{c}\text { Minimum output } \\
\text { current (A) }\end{array}$ & $\begin{array}{c}\text { Maximum output } \\
\text { current (A) }\end{array}$ & $\begin{array}{c}\text { Rated current } \\
(\mathrm{A})\end{array}$ & $\begin{array}{c}\text { Rated } \\
\text { utilization } \\
\text { factor }(\%)\end{array}$ & Power factor & $\begin{array}{c}\text { Rated power } \\
(\mathrm{KW})\end{array}$ \\
\cline { 2 - 6 } $\begin{array}{c}\text { Welding } \\
\text { rod }\end{array}$ & Grades & Diameter(mm) & & 60 & 0.86 & 14.4 \\
\cline { 2 - 6 } & $\mathrm{J} 607 \mathrm{RH}$ & 3.2 & & & \\
\hline \multirow{2}{*}{ Rail track } & Grades & Specific heat $(\mathrm{C})$ & $\begin{array}{c}\text { fusion latent } \\
\text { heat }(\mathrm{KJ} / \mathrm{Kg})\end{array}$ & $\begin{array}{c}\text { Melting point } \\
\left({ }^{\circ} \mathrm{C}\right)\end{array}$ & $\begin{array}{c}\text { Gravity } \\
\left(\mathrm{Kg} / \mathrm{cm}^{3}\right)\end{array}$ \\
\cline { 2 - 6 } & $\mathrm{E} 360$ & $0.64 \mathrm{KJ} / \mathrm{Kg}^{\circ} \mathrm{C}$ & 271.83 & 1535 & 0.00785 \\
\hline
\end{tabular}

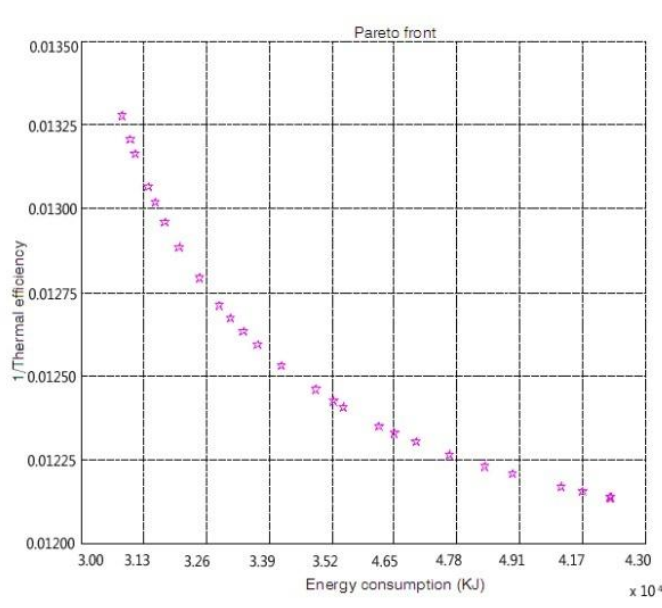

(a) Optimization solutions of FSGA.

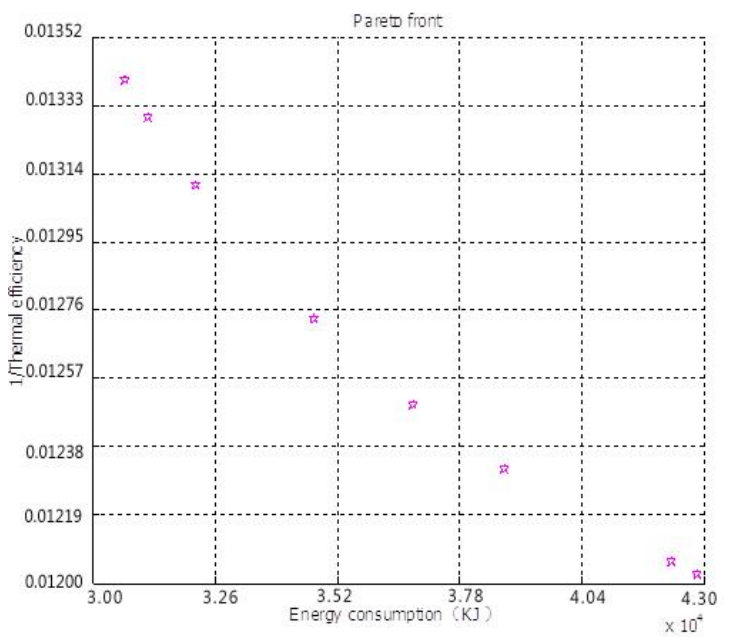

(b) Optimization solutions of GA.

Figure 3 Optimization solutions of FSGA and GA

Table 2. Corresponding detailed information of optimization solutions

\begin{tabular}{cccccc}
\multicolumn{5}{c}{ Table 2. Corresponding detailed information of optimization solutions } \\
\hline No. & $\begin{array}{c}\text { Welding current } \\
(\mathrm{A})\end{array}$ & $\begin{array}{c}\text { Welding voltage }(\mathrm{V}) \\
\text { Welding velocity } \\
(\mathrm{mm} / \mathrm{s})\end{array}$ & $\begin{array}{c}\text { Energy consumption } \\
(\text { KJ })\end{array}$ & $\begin{array}{c}\text { Thermal efficiency } \\
(\%)\end{array}$ \\
\hline 1 & 100.00 & 24.00 & 2.79 & 31200.00 & 74.35 \\
2 & 102.04 & 24.08 & 2.99 & 31942.60 & 75.28 \\
3 & 103.66 & 24.15 & 3.24 & 32544.06 & 75.16 \\
4 & 105.75 & 24.23 & 3.56 & 33310.19 & 75.34 \\
5 & 106.86 & 24.27 & 3.78 & 33715.40 & 74.56 \\
6 & 108.61 & 24.34 & 3.98 & 34366.38 & 76.59 \\
7 & 110.24 & 24.41 & 4.14 & 34982.46 & 75.75 \\
8 & 112.64 & 24.51 & 4.37 & 35890.48 & 75.78 \\
9 & 113.57 & 24.54 & 4.65 & 36231.10 & 76.32 \\
10 & 114.85 & 24.59 & 4.91 & 36714.10 & 78.25 \\
11 & 115.69 & 24.63 & 5.10 & 37042.78 & 76.71 \\
12 & 117.01 & 24.68 & 5.34 & 37542.10 & 76.16 \\
13 & 117.95 & 24.72 & 5.77 & 37901.35 & 76.58 \\
14 & 118.24 & 24.73 & 6.03 & 38012.36 & 76.57 \\
15 & 119.47 & 24.78 & 6.24 & 38484.20 & 80.58 \\
16 & 120.43 & 24.82 & 6.32 & 38853.56 & 77.78 \\
17 & 122.52 & 24.90 & 6.42 & 39661.00 & 76.49 \\
\hline
\end{tabular}




\begin{tabular}{cccccc}
\hline 18 & 123.79 & 24.95 & 6.64 & 40153.86 & 79.25 \\
19 & 124.58 & 24.98 & 6.89 & 40461.29 & 81.1 \\
20 & 125.04 & 25.00 & 7.11 & 40640.60 & 79.31 \\
21 & 125.98 & 25.04 & 7.24 & 41007.70 & 81.02 \\
22 & 126.34 & 25.05 & 7.32 & 41148.53 & 81.68 \\
23 & 127.48 & 25.10 & 7.40 & 41595.40 & 80.91 \\
24 & 128.69 & 25.15 & 7.56 & 42071.18 & 81.93 \\
25 & 129.03 & 25.16 & 8.02 & 42205.15 & 82.35 \\
26 & 129.98 & 25.20 & 8.54 & 42580.10 & 82.53 \\
\hline
\end{tabular}

\section{Results and Discussions}

The results in Figure 3(a) show that the optimization solutions are not unique. It is because that the two objectives (energy consumption and thermal efficiency) are contradictory with each other, namely the increase of one objective may cause the decrease of the other. Therefore, each point in Figure 3(a) should be seen as a non-inferior solution of this multi-objective optimization model, and the corresponding welding parameters of these solutions are listed in Table 2. Moreover, the trend of the optimization objectives and the independent variables are given in Figure 4 to illustrate the optimization results respectively.

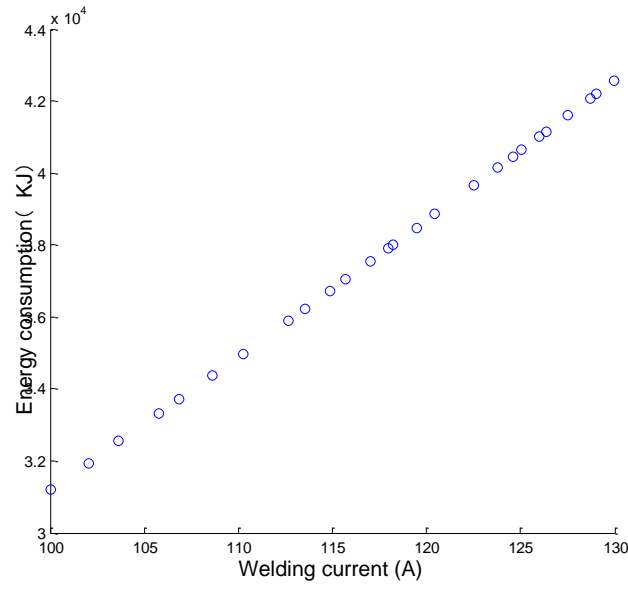

(a) Welding current vs. Energy consumption

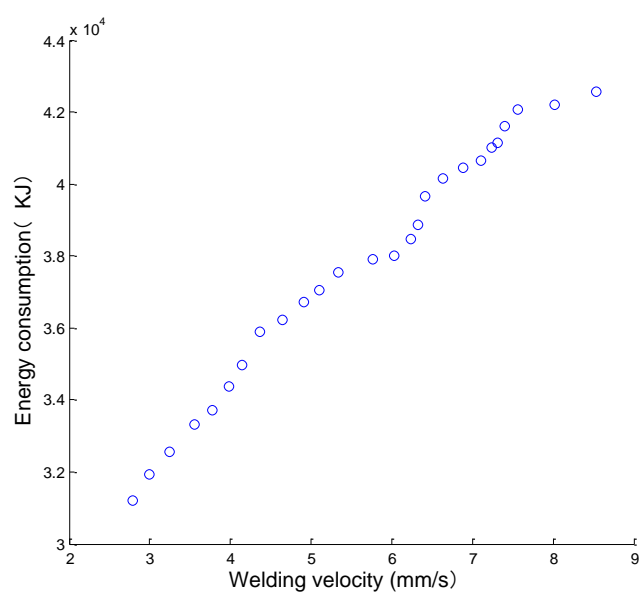

(c) Welding velocity vs. Energy consumption

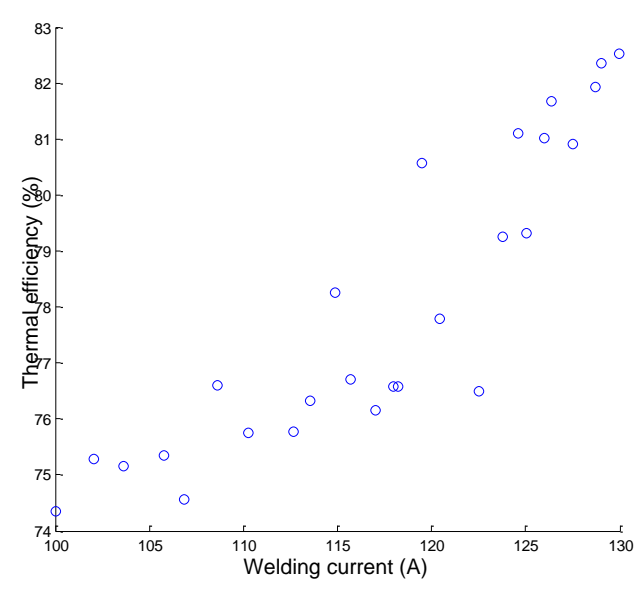

(b) Welding current vs. Thermal efficiency

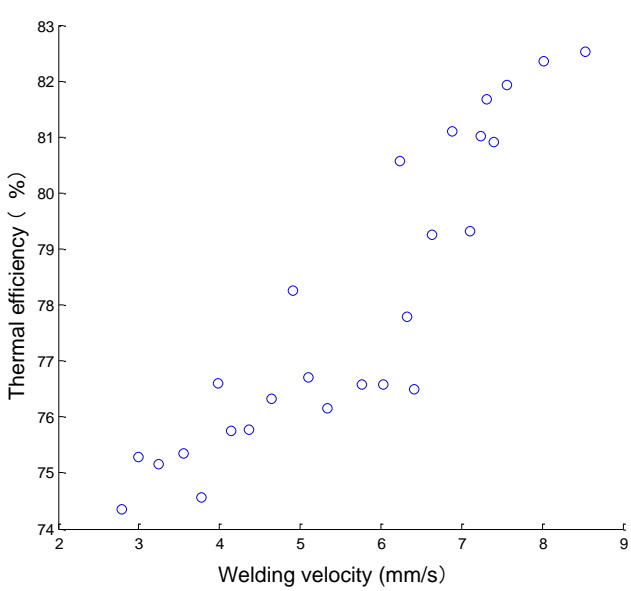

(d) Welding velocity vs. Thermal efficiency Figure 4 Trend of energy consumption and thermal efficiency 
As shown in Figure 4, energy consumption and thermal efficiency increase with the increase of welding current and welding velocity. It reflects the noninferiority of the solutions, and the feasibility of the proposed approach. Additionally, the change of welding current and welding velocity are small due to the limitations of the welding machines and SMAW process. It implies that the major factors for energy consumption and thermal efficiency are welding equipment and process, and the proposed approach can be regarded as a potential mining method for existing equipment and process without any extra investment.

Moreover, in order to illustrate the energy saving effect and the practicality of this optimization approach, further analyses are undertaken as described in the following two sections.

\section{a) Analyzing of the optimization results with the actual measuring results}

In the actual welding process of this case study, the welding current and welding velocity are obtained from operators, energy consumption is measured with the power analyzer YOKOGAWA WT1800, and thermal efficiency is calculated with the measuring data. The parameters and measuring data of the actual welding process are listed in column 4 of Table 3.

For a more focused study, the optimization solution corresponding to minimum energy consumption and maximum thermal efficiency, which are listed in column 2 and column 3 in Table 3, are taken for comparative analysis with the actual data.

Table 3 Optimization results and the actual data

\begin{tabular}{lccc}
\hline \multicolumn{1}{c}{ Welding parameters } & $\begin{array}{c}\text { Minimum energy } \\
\text { consumption }\end{array}$ & $\begin{array}{c}\text { Maximum thermal } \\
\text { efficiency }\end{array}$ & $\begin{array}{c}\text { Measured } \\
\text { parameters }\end{array}$ \\
\hline Welding current (A) & 100.00 & 129.98 & 120.00 \\
Welding voltage (V) & 24.00 & 25.20 & 25.00 \\
Welding velocity (mm/s) & 2.79 & 8.54 & 5.60 \\
Energy consumption (KJ) & 31200.00 & 42580.10 & 39452.00 \\
Thermal efficiency $(\%)$ & 74.35 & 82.53 & 77.92 \\
\hline
\end{tabular}

Comparing columns 2 and 4, energy consumption of this welding process was reduced by $20.92 \%$, but thermal efficiency is also reduced by $4.58 \%$. With respect to columns 3 and 4 , while thermal efficiency increases by $5.92 \%$, but energy consumption increases a relatively higher amount by $7.93 \%$. It shows that if the parameters in columns 2 are chosen for this case, energy consumption will reduce $8252 \mathrm{KJ}$, and if the parameters in columns 3 are chosen, thermal efficiency will increase $4.61 \%$ than the use of the existing parameters. The comparison results show that the proposed approach offers significant improvements for energy saving and thermal efficiency. However, because of the contradiction of the two objectives, minimum energy consumption and maximum thermal efficiency cannot be achieved at the same time, the optimization solutions could be used as guidance to trade off energy consumption and thermal efficiency.

Therefore, the proposed approach not only has a remarkable effect, but also provides a parameter selection space to the operators to get the appropriate welding parameters for energy saving and thermal efficiency improving.

\section{b) Comparative analysis of FSGA and GA}


In order to illustrate the performance of the proposed approach, this multi-objective optimization model is also solved with GA, the result are shown in Figure 3(b). Comparing Figures 3(a) and 3(b), it can be deduced that:

a) The results of FSGA have better fitness to the Pareto front, which means that the optimization solutions of FSGA have a better distribution uniformity than GA.

b) The final results of FSGA have 26 sets whereas the corresponding solution sets for GA is 9, this means that the population diversity and global search capacity of FSGA is better than GA.

The results show that FSGA can provide a better election strategies diversity protection mechanism than GA, which can ensure FSGA to find both the local and global optimal solutions of the multi-objective optimization problem.

\section{Conclusions}

A parameters optimization approach of arc welding process to reduce energy consumption and improve thermal efficiency is presented. In the multi-objective optimization model of arc welding process, the total energy consumption and thermal efficiency are selected as optimization objectives, and the welding current and welding velocity are chosen as independent variables. FSGA is applied to solve the optimization problem and a case study is used to validate the proposed model.

The results of the case study show that the proposed approach could produce significant improvement for energy saving and thermal efficiency to existing equipment. It could be regarded as a potential mining method to provide a greater scope for the operator to reduce energy consumption and improve thermal efficiency of arc welding process without any extra investment. Further, the case study shows that FSGA has a better population diversity capacity and global search capacity than GA.

\section{Acknowledgments}

The authors are grateful to the financial support for this research from the National Science Foundation, China (No. 51275365), the National High-Tech R\&D Program, China (No. 2014AA041504) and the Foundation of Wuhan University of Science \& Technology (2015X2049).

\section{References}

Ai Y. Y, Kong F.C, Qin J, Zeng L.Y, 1983. The electric energy consumption study of AC and DC arc welding and $\mathrm{CO}_{2}$ welding. Electric welding machine 6, 23-26

China Electrical Equipment industry Association (CEEIA), 2012. The economic operation analysis report for electric welding machine industry.

Deb K,1989. Genetic Algorithms in Multimodal Function Optimization. (Masters thesis, Dept. Engineering Mathematics, Univ. Alabama.) TCGA Report No. 890002.

Dey V, Pratihar D.K, Datta G.L, Jha M.N, Saha T.K, Bapat A.V, 2009. Optimization of bead 
geometry in electron beam welding using a Genetic Algorithm. Journal of materials processing technology $209,1151-1157$

Du Y.B, Yi Q, Li C.B, Liao L, 2015. Life cycle oriented low-carbon operation models of machinery manufacturing industry. Journal of Cleaner Production 91, 145-157.

Eagar T W, 1990. An iconoclast's view of the physics of welding rethinking old ideas. Recent trends in welding science and technology, ASM International, 341-346

Feng J.C, Li L.Q, Chen Y.B, Lei Z.L, Qin H, Li Y, 2012. Effects of welding velocity on the impact behavior of droplets in gas metal arc welding. Journal of Materials Processing Technology $212,2163-2172$

Goldberg, D.E, Richardson, J.T, 1987. Genetic Algorithms and their Applications: Proceedings of the Second International Conference on Genetic Algorithms and Their Applications, 41-49

Gonçalves C.V, Carvalho S.R, Guimarães G, 2010. Application of optimization techniques and the enthalpy method to solve a 3D-inverse problem during a TIG welding process, Applied Thermal Engineering 30, 2396-2402

Guan Q, Peng W.X, Liu J.D, Shao Y.C, He W.L, 1982. The effective utilization rate test method for welding heat source. Transactions of the China Welding Institution 3(1), 10-24.

International Energy Agency, 2007. Tracking industrial energy efficiency and $\mathrm{CO}_{2}$ emission. Paris, France: OECD/IEA

Islam M, Buijk A, Rais-Rohani M, Motoyama K, 2014. Simulation-based numerical optimization of arc welding process for reduced distortion in welded structures. Finite Elements in Analysis and Design 84, 54-64

Khan M.M.A, Romoli L, Dini G, Fiaschi M, 2011. A simplified energy-based model for laser welding of ferritic stainless steels in overlap configurations. CIRP Annals - Manufacturing Technology 60, 215-218

Kilian, L., 2008. The economic effects of energy price shocks. Journal of Economic Literature 46, 871-909.

Kumar N, Rudrapati R, Pal P.K, 2014. Multi-objective optimization in through laser transmission welding of thermoplastics using grey-based taguchi method. Procedia Materials Science 5, $2178-2187$

Liu L.M, Hao X.F, Song G, 2006. A New Laser arc Hybrid Welding Technique Based on Energy 
Conservation. Materials Transactions 47(6), 1611-1614

Luis M.T.T, Felipe A.R.V, Victor L, Rolando P.A, 2011. Multi-objective optimization of a welding process by the estimation of the Pareto optimal set. Expert Systems with Applications 38, $8045-8053$

Luo Y, Cao H.J, Li H.C, Cheng H.Q, 2013. Carbon emission model and parameter optimization of CO2 Shielded Welding Based on GRNN. China Mechanical Engineering 24(17), 2398-3402

National standard of P.R.C, 1990. Weld outerdimesions for steel construction. No. GB 10854-89.

National standard of P.R.C, 2004. Arc welding equipment - Part1: Welding Power Sources. No. GB15579.1-2004

National standard of P.R.C, 2010. The general specification for arc welding machines. No. GB/T 8118-2010.

Tang D, Du K, Li L, 2006. On the development path of Chinese manufacturing industry based on resource restraint. Jiangsu Social Sciences 4, 51-58.

Wang H.G, 2010. The handbook of practical welding process. Chemical Industry Press.

Wang H.X, 2007. Thermal efficiencies of fusion welding processes. Welding \& Joining 10, 15-19

Wang Q, Kuang L.Z, Zeng S.B, 2010. Grey relational analysis of the most optimal parameters of welding process based on arc signals. Electric welding machine 3,75-78

Wu X.L, Sun S.D, Yu J.J, Zhang H.F, 2005. Research on multi-objective optimization for flexible job shop scheduling. Computer Integrated Manufacturing System 12(5): 731-736

Xiao H.N, Lou P.H, Wu X, Qian X.M, 2012. Unidirectional guided-path network design method based on hybrid genetic algorithm. Computer Integrated Manufacturing System 18(5): $1031-1037$ 